\section{MEAT IN GREAT BRITAIN}

$\mathrm{T}$

HE British consumer recognizes very clearly that war conditions have brought about marked changes in the kind as well as the quantity of meats we eat. The British farmer realizes the changes that have taken place under war controls in the methods of marketing the meat products of his farm. The former may long for the freer choice of kind, quality and price of pre-war times; the latter may wonder how far the present marketing systems foreshadow post-war schemes. Both are in doubt as to the supplies which may be available, and probably neither completely comprehends the broad complexity of the home supply-distribution situation, as it affects the home-market position. Moreover, meat is, in normal times, a foodstuff in which individual preferences for quality, as well as of purpose and price, are allowed wide play. The pie or the pot, the stew or the roast, an ' $r$ ' or no ' $r$ ' in the monthwhile such preferences can be signs of the housewife's whim, or her purse, they can also be factors affecting supply and distribution.

At a meeting of the British Society of Animal Production, held on February 21, the meat situation in Great Britain was reviewed from three main aspects, the leading papers being: on supplies, by Major W. H. Warman and Mr. R. W. Pomeroy; on carcass quality and grading, by Dr. E. H. Callow; and on the marketing and distribution of homeproduced meat and livestock, by Mr. T. J. Shaw.

Before the War, Great Britain consumed, in addition to her own production, about 90-95 per cent of the world's exported surplus of meat. Advances in processing techniques have given us chilled, frozen, boned and canned meats. Whatever the country of origin of the imported meat, its production, processing, grading, transport and distribution were organized towards meeting fairly specific consumer demands, which formed only part of the home-consumption market. In contrast, British home production was all absorbed here in its wide variety of kinds, weights, qualities and prices. Again, owing to, or coincident with, the canalization of the whole industry in exporting countries, the treatment and utilization of edible and inedible offals have become highly developed and contribute to the efficiency and economy of the processing system. In contrast there were, before the War, just over $16 \frac{1}{2}$ thousand slaughterhouses, private and municipal, handling roughly $17 \frac{1}{2}$ million carcasses which formed the home supply of Great Britain. Further, within Great Britain we have fairly well defined importing and exporting areas; for example, the populous conurbations, as against Scotland and the south-west of England, respectively. So far as stock movements are concerned, there were frequent changes in ownership, not necessarily connected with changes in the condition of the stock; for example, store stock could change hands several times as stores, and partly fattened animals pass from one owner to another without progressing much towards the 'finished' slaughter stage. Also, the question of the effect of movement of fat stock on the quality of the carcass still needs investigation; for the best results and the most efficient supply service, should finished stock be slaughtered in the producing areas or in the consuming areas?

In relation to consumer's preferences the general trends up to 1939 were towards youth rather than to age, to tenderness rather than flavour, and to lighter weights rather than large cuts. Geographical variations complicated the situation; thus while the Midlands and the north preferred large pork and bacon carcasses, London and the south favoured pork of about $60-80 \mathrm{lb}$. weight. Moreover, even with the wide use of feeding-stuffs imported from overseas, there were marked seasonal fluctuations in the kinds of meat produced here: stall-fed winter beef, autumn grass-fed beef, lamb from the arable flocks of the south in spring, hill lambs and ewe mutton later in the year, and older lambs bred on the hills but fattened on root grounds still later, and on into the first months of the year. Also, in spite of these trends we consumed-we had to, though Lancashire liked to-considerable quantities of cow beef, thereby absorbing the high wastage in our milk-producing herds.

War economy has imposed severe changes on this general structure. The emphasis is on quantityweight rather than quality. The exclusion of imported feeding-stuffs has placed reliance on homegrown fodders, and revealed a 10 per cent fluctuation in autumn weights between good grazing seasons and bad. Fat stock pass into control at local collecting centres at which the basis of payment is fixed according to grading schedules. Local consumption, apart from supplies originating overseas, is closely related to local production.

The results of these measures of control were soon manifest in all classes of meat, but in one respect the harvest is still to appear-the emphasis on dairy stock which attends the priority given to milk production is judged to lead, with herd wastage still high, to a relative increase in the beasts with inferior capacity to give good beef. Yet nuclei of good beefbreeding types remain, and our presently diminished pig and sheep stocks still contain those types upon which, by appropriate use and from suitable combinations in cross-breeding, the British meat-producing industry could be rebuilt in its multiplicity of kinds and qualities.

If the post-war rehabilitation and form of the meatproducing industry of Britain are to be grossly in fluenced by the use of imported feeding-stuffs, the questions of available shipping and of available exchange will be prominent. Also, but by no means independent of these, there is the long-term trend for many of those countries which have in the past exported feeding-stuffs to prefer to convert those feeds to carcasses at home, and thus to export, for example, their cereal grains as meat, of higher cash value per unit weight. Behind all, there lie the possible and prospective changes in methods of production and local consumption and demand in the areas from which our meat imports were derived.

This review only touches upon some of the major topics which emerged in the general discussion; it may indicate how the problems are interlaced and the need for much further precise information. Fortunately, there has been a steady accumulation of data which tend to resolve the elusive problems of meat quality and to elucidate the relationships of growth, fattening and food values. In this direction, at least, the scientific principles on which the characteristics of the consumers' demands can be interpreted back to the producer are becoming revealed, and the exposition of the results of recent work in this field at the Low Temperature Research Station at Cambridge made a valuable contribution to the proceedings.

It is hoped that a full report will shortly be pub. lished by the Society. 